Journal of Composite Materials

\title{
Well-defined silicone-titania composites with good performances in actuation and energy harvesting
}

\begin{tabular}{|c|c|}
\hline Journal: & Journal of Composite Materials \\
\hline Manuscript ID: & JCM-12-0229 \\
\hline Manuscript Type: & Original Manuscript \\
\hline Date Submitted by the Author: & 18-Mar-2012 \\
\hline Complete List of Authors: & Cazacu, Maria; Inorganic Polymers \\
\hline Keywords: & composite, silicone, electroactive polymer , actuation, energy harvesting \\
\hline Abstract: & $\begin{array}{l}\text { Although possess low dielectric constant, silicones are between the most } \\
\text { used polymer in actuation due to their appropriate mechanical properties } \\
\text { (low modulus and high elongation). These can be easily tuned by the } \\
\text { preparation strategy: proper choice of the molecular mass and } \\
\text { microstructure of the polymer matrix; adding or not of more or less active } \\
\text { fillers; whether these are incorporated in the polymeric matrix (ex situ) or } \\
\text { generated in situ; crosslinking mode (through the side or ending functional } \\
\text { groups) or mechanism (condensation, radicalic or by hydrosilylation). A } \\
\text { relatively low cost and easy scalable procedure was used in this paper to } \\
\text { prepare silicone composites based on high molecular weight } \\
\text { polydiorganosiloxane copolymer and hydrophobized silica and titania } \\
\text { nanoparticles. The matrix polymer was synthesized by bulk ring opening } \\
\text { copolymerization of different substituted cyclosiloxanes and characterized } \\
\text { by FTIR, } 1 \mathrm{H} \text { NMR and GPC. The composites prepared by the mechanical } \\
\text { incorporation of the fillers were crosslinked by radicalic mechanism and } \\
\text { investigated by dielectrical spectroscopy, mechanical tests, dynamo- } \\
\text { mechanical analysis (DMA), dynamic vapors sorption (DVS). The actuation } \\
\text { measurements revealed displacement values in the range: } 0.04-5.09 \\
\text { nm/V/mm, while energy harvesting measurements revealed impulse } \\
\text { electrical voltage in the range } 6-20 \text { for a dynamic force of } 0.1-1 \mathrm{Kgf} \text {. The } \\
\text { robustness of these composites supported by their thermal, mechanical } \\
\text { and surface properties recommends them for use inclusively in harsh } \\
\text { environmental conditions, when their behavior is not significantly affected. }\end{array}$ \\
\hline
\end{tabular}

\section{SCHOLARONE ${ }^{m}$ \\ Manuscripts}




\title{
Well-defined silicone-titania composites with good performances in actuation and energy harvesting
}

\author{
Maria Cazacu $^{\mathrm{a}^{*}}$, Mircea Ignat ${ }^{\mathrm{b}}$, Carmen Racles $^{\mathrm{a}}$, Mariana Cristea ${ }^{\mathrm{a}}$, Valentina Musteata ${ }^{\mathrm{a}}$, Dragos \\ Ovezea $^{\mathrm{b}}$, Daniel Lipcinski ${ }^{\mathrm{b}}$ \\ a "Petru Poni" Institute of Macromolecular Chemistry, Aleea Gr. Ghica Voda 41A, Iasi, 700487, \\ Romania \\ ${ }^{b}$ National Institute for Research and Development in Electrical Engineering ICPE-CA, 313 Splaiul \\ Unirii, Bucharest, 030138, Romania
}

\begin{abstract}
Although possess low dielectric constant, silicones are between the most used polymer in actuation due to their appropriate mechanical properties (low modulus and high elongation). These can be easily tuned by the preparation strategy: proper choice of the molecular mass and microstructure of the polymer matrix; adding or not of more or less active fillers; whether these are incorporated in the polymeric matrix (ex situ) or generated in situ; crosslinking mode (through the side or ending functional groups) or mechanism (condensation, radicalic or by hydrosilylation). A relatively low cost and easy scalable procedure was used in this paper to prepare silicone composites based on high molecular weight polydiorganosiloxane copolymer and hydrophobized silica and titania nanoparticles. The matrix polymer was synthesized by bulk ring opening copolymerization of different substituted cyclosiloxanes and characterized by FTIR, ${ }^{1} \mathrm{H}$ NMR and GPC. The composites prepared by the mechanical incorporation of the fillers were crosslinked by radicalic mechanism and investigated by dielectrical spectroscopy, mechanical tests, dynamo-mechanical analysis (DMA), dynamic vapors sorption (DVS). The actuation measurements revealed displacement values in the range: $0.04-5.09$ $\mathrm{nm} / \mathrm{V} / \mathrm{mm}$, while energy harvesting measurements revealed impulse electrical voltage in the range 6-20 for a dynamic force of $0.1-1 \mathrm{Kgf}$. The robustness of these composites supported by their thermal, mechanical and surface properties recommends them for use inclusively in harsh environmental conditions, when their behavior is not significantly affected.
\end{abstract}

Keywords: composite; silicone; electroactive polymer; actuation; energy harvesting.

\footnotetext{
* Corresponding author. Dr. Maria Cazacu, Petru Poni" Institute of Macromolecular Chemistry, Iasi, Romania; Fax: +40232211299; e-mail: mcazacu@icmpp.ro
} 


\section{Introduction}

Electroactive polymers (EAP) constitute a promising family of smart materials that, among others, are able to respond to electrical stimulation with large deformations. They are dynamic actuators of high interdisciplinary interest [1]. Despite their lower stability and durability in comparison with their inorganic counterparts (i.e., ceramics), polymers have many attractive characteristics. They are generally lightweight, inexpensive, fracture tolerant, compliant, and have a large strain, elastic energy density, and high energy conversion efficiency. They can be configured into almost any conceivable shapes and their properties can be tailored to suit a broad range of requirements [2,3]. The most attractive feature of EAPs is their ability to emulate biological muscles offering resilience, toughness, large actuation strain and inherent vibration damping conferring them a great potential for development of biologically inspired robots. Because of this similarity, EAPs have gained the name "Artificial Muscles". Biomimetic robots actuated by EAP can be made highly maneuverable, noiseless and agile, with various shapes [4]. Besides actuation, EAPs have been proposed for harvesting energy consisting in conversion of ambient (e.g., solar, thermal, wind, salinity gradients,) and kinetic energies into electrical one. There are many EAP materials, in general they being divided into two major groups depending on their activation mechanisms: ionic (wet) involving mobility or diffusion of ions and electronic (dry) driven by electric field or Maxwell forces [4,5].

One particular class of EAPs is constituted by dielectric elastomers. Due to intrinsic viscoelesticity, they are able to deform reversibly under stress generating strains (several hundred percent) greater than those obtainable with other types of EAP, as well as considerable stresses and low response times [6]. These occur at high speeds and high yield strain compared with other materials. Deformation induced by an electric field is influenced primarily by the moduli and dielectric constants of elastomers in a coupled manner. At ambient temperatures, the elastomers are thus relatively soft having notably low Young modulus (about 3MPa) compared with other materials [7]. The dielectric constant can be tuned by the structure and composition of the elastomer.

Actuators and actuator materials have several important performance parameters including energy density, specific energy density, strain, actuation pressure, response time, and efficiency. To this list must be added practical considerations such as environmental tolerance, fabrication complexity, and reliability [8].

Silicone rubber is a well-known dielectric elastomer which is used in actuators [9]. In fact, due to their outstanding properties (low surface energy or surface tension, water repellence, resistance to oxygen, ozone and sunlight irradiation and, as a result resistance to weathering and ageing, shear 
stability, excellent dielectric strength, low toxicity), silicones are present in many objects that we are using in our daily life from automotive, electric and electronics, to domestic appliances [10]. Their acceptance by wide public is due, besides their behavior and good performance at extreme (high/low) temperatures and minimal temperature effect on the properties, to the environmental compatibility during manufacture and use [11]. It has been proved that the microorganisms degrade silicones to silicone fluids and other compounds or even to $\mathrm{SiO}_{2}$ under the effect of UV light. The burning products are $\mathrm{SiO}_{2}, \mathrm{CO}_{2}$ and water that are the most common found in nature [12]. These materials are biologically-compatible and posses useful medical and engineering properties [13]. Silicone elastomers are easily processable (by spin coating, casting, injection, moulding, or extrusion, depending on the consistence and end use). Their good elastomer behavior is due to the high mobility of the Si-O bonds, which confer high flexibility to main chains [14]. Polydimethylsiloxane is homogeneous, isotropic, and optically transparent down to about $300 \mathrm{~nm}$ [15]. Silicones are odorless, colorless and water resistant.

Several commercial silicones were already investigated regarding their use as EAPs. Silicones have the disadvantages of low dielectric constant which requires increased activation voltages to obtain reasonable actuation effects and low fracture resistance which makes difficult the handling of thin films [16]. Fillers are used to enhance both mechanical and electrical properties of the silicone rubbers [17]. In general, room temperature vulcanization formulations based on low molecular weight polydimethylsiloxane were used in actuation. As a result, either addition (hydrosilylation) or condensation mechanisms were used to convert the fluid compounds in silicone elastomers.

Different from the most of the reported silicone actuators, in this paper we used a home prepared polydiorganosiloxane copolymer, polydimethylmethylvinyl- $\alpha, \omega$-diol of high molecular mass requiring peroxidic crosslinking at high temperature. In order to improve the mechanical properties, the polymer was also reinforced with fumed silica after which $\mathrm{TiO}_{2}$ nanoparticles were incorporated in different percents in order to increase the dielectric constant of the silicone elastomer taking into account the high value of the relative permittivity for $\mathrm{TiO}_{2}$ (114). It has been proved that the presence of $\mathrm{TiO}_{2}$ in silicone composites enhances maximum strain, and reduces tensile strength and modulus [18]. In addition, $\mathrm{TiO}_{2}$ can confer anti-UV radiation property [19]. Both silica and titania previously hidrophobized were incorporated in well-characterized polysiloxane matrix by mechanical mixing followed by moulding and crosslinking with 2,4-dichlorobenzoyl peroxide. The composites were investigated by mechanical tests, dynamo-mechanical analysis (DMA), dielectrically spectroscopy, dynamic vapors sorption (DVS). The actuation and energy harvesting measurements were performed. 


\section{Experimental}

\subsection{Materials}

Polydiorganosiloxane- $\alpha, \omega$-diol (Scheme 1) was obtained by bulk polymerization of octamethylcyclotetrasiloxane catalyzed by $\mathrm{H}_{2} \mathrm{SO}_{4}$, at room temperature, according to procedure described in ref. [20]. In order to facilitate the curing process, a small percent of vinyl-substituted cycles $\left(3 \%\right.$ wt. $\left.\mathrm{D}_{3} \mathrm{~V}\right)$ was added in the initial reaction mixture. The polymer was purified by washing with slight alkaline solution and then with water and, after which was devolatilized in vacuum at $180^{\circ} \mathrm{C}$ to remove water and low molecular weight siloxanes. The resulted product was analyzed by gel permeation chromatographic analysis, GPC, was carried out on a PL-EMD 950 Evaporative Mass Detector instrument by using $\mathrm{CHCl}_{3}$ as eluent, after calibration with standard polystyrene samples. A monomodal elution curve was obtained and the average molecular mass values estimated on its basis were: $\mathrm{Mn}=346000, \mathrm{Mw}=698000$, polydispersity index, $\mathrm{I}=2.0$. Spectral (FTIR and ${ }^{1} \mathrm{H}-\mathrm{NMR}$ ) analyses confirmed the polymer structure. Thus, in FTIR spectrum (Bruker Vertex 70 FT-IR spectrometer), the bands assigned to $\mathrm{Si}-\mathrm{O}-\mathrm{Si}$ bond at $1020-1092 \mathrm{~cm}^{-1}$ and $\mathrm{Si}-\mathrm{CH}_{3}$ at 799 and $1261 \mathrm{~cm}^{-1}$ are present. In the ${ }^{1} \mathrm{H}$ NMR spectrum (Bruker Avance DRX $400 \mathrm{MHz}, \mathrm{CDCl}_{3}$ at $25^{\circ} \mathrm{C}$ ) the peaks around $0.075 \mathrm{ppm}$ are assigned to the protons of $\mathrm{Si}-\mathrm{CH}_{3}$ groups. Due to their too low concentration, the peaks corresponding to $\mathrm{Si}-\mathrm{CH}=\mathrm{CH}_{2}$ groups, which should occur in the range 5.76-6.05 ppm are not visible in spectrum.

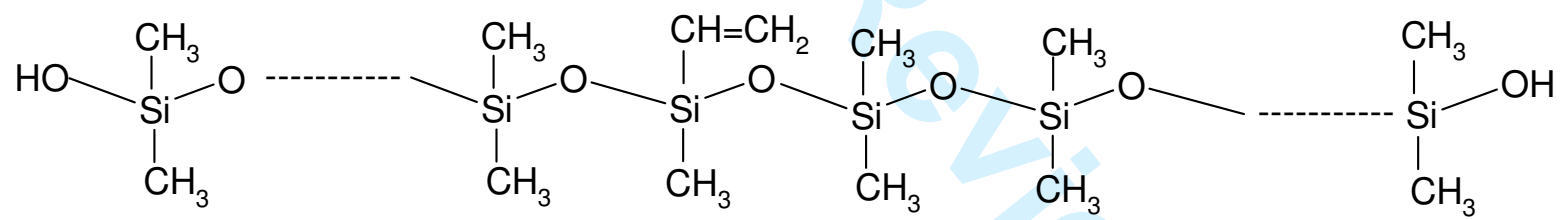

Scheme 1

Fumed silica, Aerosil 380 (Degussa), 100\% purity, specific surface $380 \mathrm{~m}^{2} / \mathrm{g}$, particle diameter $0.003-0.015 \mu \mathrm{m}$ was hydrophobized by treatment with dimethylcyclosiloxanes mixture in vapour state.

Titanium(IV) oxide, $\mathrm{TiO}_{2}$, (Fluka), 99\% purity, was dried in vacuum at $100^{\circ} \mathrm{C}$.

2,4-Dichlorobenzoil peroxide, paste $50 \%$ in silicone oil, having a critical temperature: $60-70{ }^{\circ} \mathrm{C}$ and set-cure temperature in the range $115-150{ }^{\circ} \mathrm{C}$.

\subsection{Equipments}

Stress-strain measurements were performed on dumbbell- shaped cut from thin films on a TIRA test 2161 apparatus, Maschinenbau GmbH Ravenstein, Germany. Measurements were run at an 
extension rate of $50 \mathrm{~mm} / \mathrm{min}$, at room temperature. All samples were measured three times and the averages were obtained. Hardness was measured with a digital HAD-1 Shore Hardness tester (SAUTER).

DMA tests were carried out in tension mode on a PerkinElmer Diamond device by using polymeric films with length of $10 \mathrm{~mm}$, width of $10 \mathrm{~mm}$ and thickness in the range of $1.5-2 \mathrm{~mm}$. A temperature scan from $-150{ }^{\circ} \mathrm{C}$ up to over $200{ }^{\circ} \mathrm{C}$ at a heating rate of $2{ }^{\circ} \mathrm{C} / \mathrm{min}$ and at $1 \mathrm{~Hz}$ was applied.

Novoncontrol setup (Broadband dielectric spectrometer Concept 40, Germany), integrating an ALPHA frequency response analyzer and a Quatro temperature control system, was used to investigate the dielectric properties of the polymer composites over a broad frequencies window, $10^{0}-10^{6} \mathrm{~Hz}$, in the -140 to $+50{ }^{\circ} \mathrm{C}$ temperature range. Dielectric data were collected at constant temperature as a function of frequency at every $5{ }^{\circ} \mathrm{C}$ between $-140{ }^{\circ} \mathrm{C}$ and $+50{ }^{\circ} \mathrm{C}$. The bias voltage applied across the sample was $1.0 \mathrm{~V}$. Samples having uniform thickness in the $0.7-1 \mathrm{~mm}$ range were placed between gold plated round electrodes, the upper electrode having a $20 \mathrm{~mm}$ diameter.

Water vapors sorption capacity of the film samples was measured by using the fully automated gravimetric analyzer IGAsorp supplied by Hiden Analytical, Warrington (UK). An ultrasensitive microbalance measures the weight change as the humidity is modified in the sample chamber at a constant regulated temperature. The measurement system is controlled by a software package.

The electromechanical actuation measurements were performed by non-contact procedure with the AGILENT 10766A linear interferometer system, which is able to measure with high resolution the linear micro- and nanodisplacement in section. The main characteristics: displacement resolution - 2 $\mathrm{nm}$, optical wave length $-316.5 \mathrm{~nm}$, optical efficiency - 73\%. The harvesting experiments (voltage recording) were performed by using a memory oscilloscope Tektronix DPO 4032 with two channels, at frequency of $100 \mathrm{MHz}$ and sensibility of $2 \mathrm{mV} /$ div.

\subsection{Procedure}

\subsubsection{Preparation of the composites}

The composites were prepared according to procedure described in ref. [20] by mixing the siloxane polymer with fillers, in a Yanke - Kunkel laboratory mixer equipped with palettes in Dublex system and cooling mantle. The fillers, first silica followed by titania in different percents (Table 1), were added to the polysiloxane under mixing in small portions until the whole amounts were incorporated. Finally the crosslinking catalyst (1.5\%wt. 2,4-dichlorobenzoyl peroxide) was also added.

\section{Table 1}




\subsubsection{Crosslinking}

A certain composite amount (usually about $25 \mathrm{~g}$ ) having incorporated catalyst was pressed in an iron mold 1x100x100 mm. This ensemble was kept $1 \mathrm{~h}$ at $100^{\circ} \mathrm{C}$ when the catalyst determines the crosslinking. Then, the film easily peeled off from the substrate was maintained another $3 \mathrm{~h}$ at $150^{\circ} \mathrm{C}$ in air stream to complete the crosslinking and for devolatilization.

\section{Results and discussion}

\subsection{The incorporation of the fillers}

Due to low intermolecular forces between polysiloxane chains, silicones have poor mechanic properties. These can be significantly improved by adding fine divided materials, usually inorganic powders, which act by increasing the stress for movement of the macromolecular chain [22] followed by crosslinking. Reinforcement of elastomers is generally considered to involve an increase in abrasion resistance, tensile strength, tear strength, and modulus. The most common reinforcing filler used in silicone elastomers is amorphous silica [21]. A silica aerogel previously hydrophobized by treatment with a low molecular siloxane was added to the polysiloxane matrix in this case in $28 \%$ by weight.

Polydimethylsiloxanes and silicones in general have low dielectric constant (cca. 2-3). In order to be effective as an electroactive polymer, an inorganic oxide, titanium dioxide, having high dielectric constant was incorporated in different percents in the above prepared silicone matrix. Three blank samples consisting in pure crosslinked PDMS (M1), crosslinked PDMS containing silica only (M2), and crosslinked PDMS containing titania only (T3) were also prepared.

\subsection{Crosslinking}

In order to convert the plastic composite into elastomer, the crosslinking is needed, the process being also known as vulcanization or curing. Elastomers are lightly-crosslinked polymers. The mechanical behavior of an elastomer depends strongly on cross-link density. The elastomer properties, especially the modulus, are significantly changed by the cross-link density in most elastomer systems. Without cross-linking, the polymer chains have no chemical bonds between chains, and thus the polymer may flow upon heating over the glass transition temperature. If the polymer is densely crosslinked, the chains cannot flow upon heating, and a large deformation cannot be expected upon stretching. Elastomers are between these two states of [22]. In the case of the silicones, the crosslinking can occur either through ending functions of the polymeric chain or by bridges along the main polymer chain. The (co)polymer prepared in this paper being of high molecular mass, the first crosslinking path 
is not sufficient, so we used the second curing procedure in presence of 2,4-dichlorobenzoyl peroxide. This is highly active peroxide for saturated siloxanes, having a critical temperature in the range 60-70 ${ }^{\circ} \mathrm{C}$ and set-cure temperature of $115^{\circ} \mathrm{C}[22]$.

It is presumed that during radicalic crosslinking, bridges are formed between vinyl and methyl groups [22] along the main polymer chains (Scheme 2).

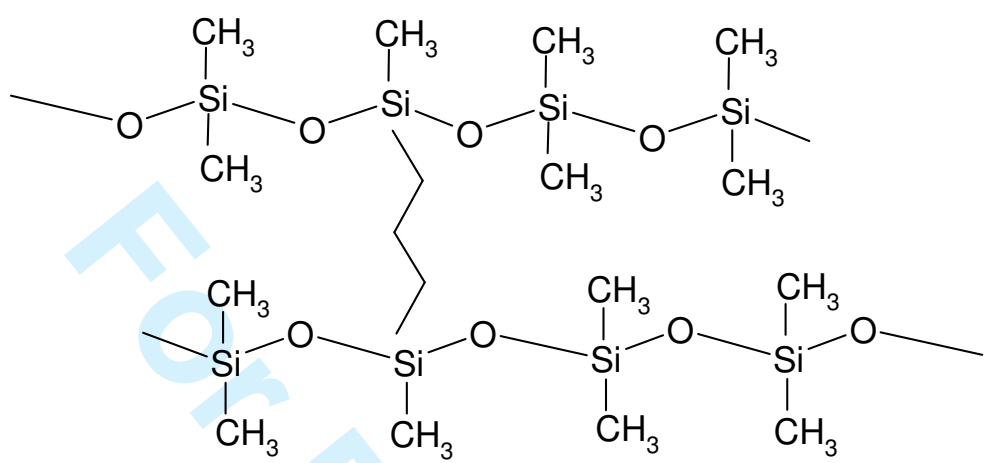

Scheme 2. A fragment of peroxidic crosslinked polymer.

The crosslinking density can be adjusted by the kinetic variables of vulcanization reactions such as peroxide content, reaction time, reaction temperature, catalyst (or accelerator), etc., the elastomer vulcanization being a kinetically controlled process in most cases [12] not a thermodynamic one.

The properties of the crosslinked films were investigated. Young modulus, elongation, relative permittivity are mainly of interest for actuation and energy harvesting. These as well as other parameters useful for their proper operation were estimated by specific measurements as following.

\subsection{Mechanical tests}

Mechanical tests permit registration of stress strain curves that provide information about the polymer's mechanical properties such as the brittleness, elasticity and yield strength of the polymer. Specimens for tensile measurements were cut out from the thick films using a V cutter. Stress strain curves are presented in Figure 1, while the main parameters determined on their basis are summarized in Table 2.

\section{Figure 1}

\section{Table 2}


Values obtained for tensile strength for our silica-titania filled samples ranges between 2.79-4.89 $\mathrm{MPa}$. These are higher than values obtained for blank samples M1 and M2. The unfilled PDMS has the lowest value for the tensile strength, $0.31 \mathrm{MPa}$, as expected. By adding $28 \%$ silica, this value increases at 1.24 MPa. Instead, it seems that, the co-existence of the silica and titania has a synergetic effect on the tensile strength.

The Young modulus, E, determined from the stress-strain curve by calculating the ratio of stress to strain when this attains $10 \%$ from the total elongation has values between 0.97 and $1.42 \mathrm{MPa}$. The modulus values of the silicone-silica-titania composites are almost double that of M1 sample consisting of pure crosslinked PDMS and about five times higher than the sample T3 based on crosslinked PDMS filled with $\mathrm{TiO}_{2}$ only. Elongation increases from $312 \%$ to $635 \%$ when the titania content amounted from 2 to $50 \%$ wt. The average hardness of the samples ranges from 72.6 to 86 ShA. By examining the hardness values it can be observed that this is conferred in principal by the presence of the silica as well as by the co-existence of the silica and titania. Single titania reduces the values of the material hardness, the samples based on the PDMS and titania only showing the lowest value for the hardness, 46.5 ShA.

3.4. Dynamic mechanical analysis provides the variation of the storage modulus (E'), loss modulus (E") and loss tangent $(\tan \delta)$ as a function of temperature. The drops in E' curves and the peaks of E" and tan $\delta$ plots report on the relaxations in polymers. Some illustrative curves are presented in Figure 2, while the main parameters for all samples are centralized in Table 3. At very low temperatures, close to $-150^{\circ} \mathrm{C}$, all the samples have the storage modulus (E') over $10^{8} \mathrm{~Pa}$, which indicates that all of them are in the glassy state. Until room temperature three important drops in the storage modulus take place. Broad loss modulus $\left(E^{\prime \prime}\right)$ and loss factor $(\tan \delta)$ peaks correspond to each descent of E'.

The first $\tan \delta$ peak centered in the range of $-122^{\circ} \mathrm{C} \div-126^{\circ} \mathrm{C}$ can be associated with the $\alpha-$ relaxation of PDMS chain segments. It can be seen that this value is not significantly influenced by the titania presence and content. It is not excluded that the PDMS sample contains chains segments with lower mobility. The presence of these chains explains the second $\alpha$-relaxation peak in the range $-65^{\circ} \mathrm{C}$ $-45{ }^{\circ} \mathrm{C}$. All filled samples have the melting temperature in the range $-37{ }^{\circ} \mathrm{C}--41^{\circ} \mathrm{C}$ and a slight decreasing of melting temperature can be observed by rising titania content. At room temperature, the E' values are situated around $1-2 \cdot 10^{6} \mathrm{~Pa}$, with very small differences between samples. The composites 
show good thermal stability until over $150{ }^{\circ} \mathrm{C}$ (the limit of the experimental temperature). The temperature values included in the Table 3 correspond to the middle of the peaks on $\tan \delta$ curve.

\section{Table 3}

Figure 2

Although they are estimated by methods having different principles, the Young modulus and elastic modulus values are about the same order of magnitude: 0.97-1.42 and 1.20-2.58 MPa, respectively for the PDMS-silica-titania composites.

3.5. Dielectric thermal analysis (DETA) provided information about the storage and dissipation or loss component of complex permittivity, $\varepsilon^{\prime}$ and $\varepsilon$ " respectively, of the electroactive materials in broad frequency and temperature range. Also, from their variation, thermal transitions correlated with dipolar movements are evidenced. The effects of the filler content on dielectric properties and on the segmental mobility associated with the glass transition were studied by dielectric spectroscopy for the silicone/titania composites.

\section{Figure 3}

\section{Figure 4}

The polarizability of the Si-O bond constitutes a premise for a high dielectric constant. Indeed, this is higher as compared to organic nonpolar polymers (e.g., polyethylene), but not so much as it could be due to the nature of this chemical bond. This is the effect of the side methyl groups (in the case of PDMS), which prevent Si-O dipoles from approaching each other too closely. The situation does not change too much by replacing methyl groups with more polarizable ones. Instead, it has been found that the dielectric constant of PDMS increases with the polymerization degree of the siloxane backbone before quickly reaching a plateau value [23]. The dielectric properties of silicones are good, but not exceptional in comparison with organics. The success of silicone-based products is certainly related more to their stability over a wide range of temperature, humidity and frequency [23].

Figures 3 and 4 show the comparison of dielectric constant $\left(\varepsilon^{\prime}\right)$ and dielectric loss ( $\left({ }^{\prime \prime}\right)$ for blank samples and composites T3, and 1 to 6 as a function of frequency from $1 \mathrm{~Hz}$ to $1 \mathrm{MHz}$ at room temperature. For pure crosslinked PDMS (curve a), dielectric constant has a value of about 2.9, while for the composite with $\mathrm{SiO}_{2}$ (curve b) the value of dielectric constant is approximately 3 ( $\varepsilon^{\prime} \mathrm{SiO2} \approx 3.9$ ). It can be observed that, the dielectric constant of the composites with $\mathrm{TiO}_{2}$ is substantially increased with increasing filler content, because of the high dielectric constant of $\mathrm{TiO}_{2}\left(\varepsilon^{\prime}{ }_{\mathrm{TiO} 2} \approx 114\right)$. Dielectric constants for composites 3 and $\mathrm{T} 3$, having similar $\mathrm{TiO}_{2}$ content, are nearly equal, with slightly larger values for the sample $\mathrm{T} 3$. 
Starting with composite 4, dielectric constant and dielectric loss show an increase in the lower frequency range due to the Maxwell-Wagner-Sillars (MWS) polarization processes. The large frequency dependent contribution to the dielectric response, especially at low frequencies, comes from the separation of charges at interfaces with different dielectric characteristics [24]. This effect is more accentuated for the composites with higher $\mathrm{TiO}_{2}$ content due to the larger interfacial aria. However, the observed dielectric loss values are almost one order of magnitude lower than other reported suitable for allowing sufficient transduction effects [25]. The limited MWS polarization phenomenon suggests a good compatibility between the different phases [26]. A different behavior is observed for composite T3, with a sharp increase of $\varepsilon$ " at low frequencies, due to a higher interfacial polarization. At intermediate frequencies and above, every increase of the filler volume fraction is coherently paired with a corresponding increase of $\varepsilon^{\prime}$ (Figure 3).

The observed low values of the dielectric loss indicate minimal conversion of electrical energy to heat in the dielectric material and, as a result, the electrical signals will lose less of their intensity in the dielectric medium [27].

\section{Figure 5}

In Figure 5, the dielectric constant and dielectric loss are represented as a function of temperature and frequency for sample 4. Around $-120{ }^{0} \mathrm{C}$, at $1 \mathrm{~Hz}, \varepsilon$ ' presents a steep increase and $\varepsilon$ ” a peak which corresponds to the segmental a relaxation associated with the glass transition of amorphous PDMS as was emphasized by DMA (Figure 2, Table 3). For higher frequencies, these peaks are shifted to higher temperatures, which is characteristic for dielectric relaxations. On further increasing the temperature, $\varepsilon$ ' displays a decrease that could be due to a crystallization process that produces the immobilization and/or constraint of some fractions of the responding dipoles by increasing bulk crystallinity [28].

\section{Figure 6}

Dielectric data recorded isothermally are replotted as $\varepsilon$ ” versus temperature for $1 \mathrm{kHz}$ in Figure 6, in order to facilitate comparison between composites T3 and 1-6 (Figure 6, curves c-i) and blank samples M1, M2 (Figure 6, curves a,b). One can observe that the position and shape of $\alpha$ relaxation remains almost unchanged for all the compositions. This observation is valid for all the frequencies not represented here. Several studies [29,30] on polymer nanocomposites show an increase of the glass transition temperature, suggesting that the mobility of the entire volume of the polymer is restricted by the presence of the nanoparticles. However, reduction of glass transiton temperature has also been reported [31] in the case of weak interactions between filler and polymer, and in other cases the addition of nanoparticles causes no significant change to the glass transition of the polymer presumably because effects causing increase and decrease of polymer mobility are present simultaneously and 
effectively cancel out [32,33]. At positive temperatures, dielectric loss increases with increasing filler content for samples $1-6$ due to interfacial polarization mentioned above, while for M1 and M2, $\varepsilon "(T)$ do not show large variations.

The temperature corresponding to $\alpha$ peak was determined for frequencies taken at intervals of a decade and are represented in Figure 7. These values were the same for all the samples and it was found that their dependence is well described by the Vogel-Fulcher-Tamman equation [34,35], characteristic for cooperative relaxations:

$$
f_{\text {max }}=f_{0} \exp \left(-\frac{B}{T-T_{0}}\right)
$$

where $T$ is the temperature, expressed in $\mathrm{K}$, that corresponds to maximum loss for frequency $f_{\max }$, $f_{0}, B$ and $T_{0}$ are temperature-independent empirical parameters. $T_{0}$, called Vogel temperature is the temperature at which the molecular movements associated with glass transition vanish. The best fitting was achieved for $f_{0}=4.62 \times 10^{12}, B=0.76$ and $T_{0}=130 \mathrm{~K}$. Similar $\alpha$ relaxation was observed for the other composites not represented in Figures 6 and 7.

Figure 7

\subsection{Vapor sorption capacity}

The performance and long-term stability of the EAPs depend, among others, on the water exchange with the environment. Variation of the water content in EAPs will affect the permitivity and as result the actuation response. In addition, the water presence can contribute to corrosion. In certain cases, water sorption capacity is useful in sensors but this behavior must be known and controlled. Although are known for their hydrophobicity and water repellence, due to high permeability to gases, silicones will uptake water quickly compared with epoxide resins, for example, but the water content in silicones is ten times lower than in epoxies. The adding of silica or titania in the silicone would be expected to increase the hydrophilicity of the silicones due to the presence of the $\mathrm{OH}$ groups on the surface of the particles. However, both filler were hydrophobized prior to be incorporated in the silicone matrix, as the $\mathrm{OH}$ group's effect not to occur [23]. Therefore, it is important to verify the behavior of the resulted composites in variable humidity environment.

Water vapors sorption capacity for the samples at $25{ }^{\circ} \mathrm{C}$ in the $0-90 \%$ relative humidity range (RH) was investigated by using the IGAsorp equipment. The vapors pressure was increased in $10 \%$ humidity steps, each having a pre-established equilibrium time between 10 and 20 minutes. At each 
step, the weight gained was measured by electromagnetic compensation between tare and sample when equilibrium was reached. An anti-condensation system was available for vapor pressure very close to saturation. The cycle was ended by decreasing the vapor pressure in steps to obtain also the desorption isotherms.

The drying of the samples before sorption measurements was carried out at $25^{\circ} \mathrm{C}$ in flowing nitrogen $(250 \mathrm{~mL} / \mathrm{min})$ until the weight of the sample was in equilibrium at $\mathrm{RH}<1 \%$. The sorption/desorption isotherms registered in these conditions are presented in Figure 8.

\section{Figure 8}

According to IUPAC classification, the sorption-desorption curves can be associated to type III curves. These types of isotherms describe sorption on hydrophobic/low hydrophilic material with weak sorbent-water interactions.

As can be seen in Table 4, the maximum humidity sorption capacity has low values, between 0.10 and $0.68 \%$ wt., and the small variations do not seem to be correlated with $\mathrm{TiO}_{2}$ content. The neat crosslinked PDMS shows the lowest water sorption capacity. By adding silica, the sorption capacity slightly increases from 0.10 to $0.47 \%$. The small variations in the cases of the other samples do not seem to be correlated with the $\mathrm{TiO}_{2}$ content. Low values of the water sorption capacity constitute a guarantee of good stability of the dielectric properties in an environment with variable humidity.

\section{Table 4}

\subsection{Actuation and energy harvesting measurements}

The considered actuation consists in the transformation of the electric energy directly into mechanical work producing large strains. The actuators are composed primarily of a passive elastomer film with thickness in the range $0.78-2.2 \mathrm{~mm}$ with two compliant electrodes on the surfaces, exhibiting a typical capacitor configuration. It is known that, in general the elastomers are incompressible (Poisson's ratio $=0.5$ ) and viscoelastic. When the electrical voltage is applied to the electrodes, an electrostatic force is generated between the electrodes. The force is compressive, and thus the elastomer film expands in the in-plane direction [12]. While most of the reported actuation experiments measure lateral strain resulted by electric field-induced thickness squeezing, we apply a non-contact measurement procedure by using the AGILENT 5529A system, which is able to measure the linear micro and nanodisplacement in cross-section with high resolution interferometer. This procedure is also considered better than contact ones by other authors [36]. The parameters used to estimate actuation behavior were defined as follows:

The electric field : 


$$
E[V / m m]=\frac{U}{d}=\frac{\text { Voltage }[\mathrm{V}]}{\text { Thichkness }[\mathrm{mm}]}
$$

The resolution :

$$
R_{a}[n m / V / m m]=\frac{a_{\max }[n m]}{E[V / m m]}
$$

where $a_{\max }$ - represents the maximum actuation to the maximum voltage of experiment (in our case $\mathrm{U}=500 \mathrm{~V})$.

The registrations were performed at a constant force by $22 \mathrm{cN}$. The variation of the displacement value in dependence on the applied voltage is presented in Figure 9 for all prepared samples. Although as expected, the displacement increases by applied voltage, this dependence seems to be not linearly one.

\section{Figure 9}

In Table 5 are selected the specific experimental results of microactuation parameters for investigated elastomeric samples for $500 \mathrm{~V}$ applied voltage.

\section{Table 5}

As expected, the actuation is improved as the titania content in the sample increases, being in direct correlation with mechanical (Figure 1, Table 2) and dielectric (Figures 3, 4) parameters. For example, sample 6 with highest titania content showed a gradient of $7.5 \mathrm{~nm} / \mathrm{V}$ on the voltage range 300-500 V (Figure 9), which represent a very good performance in the field of electrostrictive actuation, regardless of materials [7,25].

The harvesting test was realized to mechanical microimpulse: the fall of a microball (with the mass of $\mathrm{m}=4.08 \mathrm{~g}$ ) from a height of $0.5 \mathrm{~m}$ on the surface of the elastomeric membrane (Figure 10). The dynamic parameters taken into consideration in these conditions were:

- $\quad$ speed to the contact with the elastomeric membrane (the initial speed is 0 ):

$$
v=\sqrt{2 g h}=\sqrt{2 \cdot 9.8 \cdot 0.5}=3.162[\mathrm{~m} / \mathrm{s}]
$$

- the mechanic impulse:

$$
p=m v=12.902 \cdot 10^{-3}[N s]
$$

- the kinetic energy in contact:

$$
E=\frac{m v^{2}}{2}=20.396 \cdot 10^{-3}[J]
$$

- the microforce: 


$$
F=\frac{E}{h}=0.0407[N]
$$

\section{Figure 10}

The results of the harvesting experiment expressed as a peak to peak voltage for all samples (Table 5) indicate good values, comparable with those reported in literature for other materials [36-39]. The developed electric micropower is $\sim 7-10 \mu \mathrm{W}$ with a density in the range $7.77-11.00 \mu \mathrm{W} / \mathrm{cm}^{3}$. Based on the obtained values it seems that the co-existence of silica and titania enhances the harvesting capacity rather than each of them does alone.

\section{Conclusions}

A polydimethylsiloxane- $\alpha, \omega$-diol of high molecular mass was prepared, characterized and used as matrix to prepare composites followed by crosslinking. Silica and titania dioxides were used as fillers to improve mechanical characteristics and dielectric constant, respectively. A net increasing of the mechanical characteristics (Young modulus, tensile strength, elongation, and hardness) resulted by incorporation of $28 \%$ wt. silica, while the subsequent adding of the titania led to the increasing of the dielectric constant, and also contributes to the increasing of tensile strength and elongation. A slight decreasing of the melting temperature values and increasing of storage modulus was emphasized by DMA while glass transition is not affected by the presence of the fillers. The low dielectric and mechanical losses of the investigated silicone/titania composites make them candidates as actuator materials, where a short response time is required. The dielectric constant of composites increased with increasing filler content, while retaining the flexibility of the matrix. Low values of the sorption capacity are a guarantee of good stability of the dielectric properties in an environment with variable humidity. The actuation effect expressed as section displacement and estimated with high resolution interferometer ranges between 0.04-5.09 $\mathrm{nm} / \mathrm{V} / \mathrm{mm}$, in general increasing with increasing titania content. The energy harvesting capacity determined from the fall of a miniball on the surface of elastomeric film gave promising results.

Acknowledgements: This research occurred in the framework of European Scientific Network for Artificial Muscles, ESNAM (COST Action MP1003). 


\section{References}

1. Samatham, R.; Kim, K.J; Dogruer, D.; Choi, H.R.; Konyo, M.; Madden, J.D.; Nakabo, Y.; Nam, J.D.; Su, J.; Tadokoro, S.; Yim, W.; Yamakita, M. (2007) Active Polymers: An Overview. In: Kim KJ, Tadokoro S (ed) Electroactive polymers for robotic applications: artificial muscles and sensors, 1st ed. Springer-Verlag London Limited, pp.1-36.

2. Osada, Y.; De Rossi, D.E. (2000) Polymer Sensors and Actuators; Berlin: Springer-Verlag.

3. Bar-Cohen Y (2004) Electroactive polymer (EAP) actuators as artificial muscles: reality, potential, and challenges; Bellingham, Wash: SPIE Press.

4. Bar-Cohen, Y. (2000) Electroactive polymers as artificial muscles - capabilities, potentials and challenges. In: Osada, Y. (ed) Handbook on Biomimetics, sect. 11, NTS Inc., pp. 1-13.

5. Bar-Cohen, Y. (2005) Artificial Muscles using Electroactive Polymers (EAP): Capabilities, Challenges and Potential; Pasadena, CA : Jet Propulsion Laboratory, National Aeronautics and Space Administration.

6. Carpi, F.; Chiarelli, P.; Mazzoldi, A.; De Rossi, D. (2003) Electromechanical characterisation of dielectric elastomer planar actuators: comparative evaluation of different electrode materials and different counterloads. Sens. Actuators A 107:85-95.

7. Nam, J.D.; Choi, H.R.; Koo, J.C.; Lee, Y.K.; Kim, K.J. (2007) Dielectric elastomers for artificial muscles. In: Kim, K.J.; Tadokoro, S. (eds) Electroactive polymers for robotic applications, artificial muscles and sensors; Springer-Verlag London Limited pp. 37-48.

8. Pelrine, R.; Kornbluh, R.; Joseph, J.; Heydt, R.; Pei, Q.; Chiba, S. (2000) High-field deformation of elastomeric dielectrics for actuators. Mater. Sci. Eng. C 11:89-100.

9. Gharavi, N.; Razzaghi-Kashani, M.; Golshan-Ebrahimi, N. (2010) Effect of organo-clay on the dielectric relaxation response of silicone rubber. Smart Mater. Struct. 19(2):025002. doi: 10.1088/0964-1726/19/2/025002.

10. Jershow, P. (2002) Silicone Elastomers; Rapra Technology Ltd.

11. Kuo, A.C.M. (1999) Poly(dimethylsiloxane). In: Mark, J.E. (ed) Polymer Data Handbook; Oxford: Oxford University Press Inc., pp. 411-435.

12. Sabourin, C.L.; Carpenter, J.C.; Leib, T.K.; Spivack, J.L. (1996) Biodegradation of dimethylsilanediol in soils. Appl. Environ. Microb. 62(12) :4352-4360.

13. Rahimi, A. (2004) Inorganic and Organometallic Polymers: A Review. Iran. Polym. J. 13(2):149-164. 
14. Pelrine, R.; Kornbluh, R.; Pei, Q.; Joseph, J. (2000) High-Speed Electrically Actuated Elastomers with Strain Greater Than 100\%. Science 287(5454):836-839.

15. Xia, Y.; Whitesides, M. (1998) Soft lithography. Angew. Chem. Int. Ed. 37:550 - 575.

16. Opris, D.M.; Molberg, M.; Walder, C.; Ko, Y.S.; Fischer, B.; Nüesch, F.A.. (2011) New silicone composites for dielectric elastomer actuator applications in competition with acrylic foil. $A d v$. Funct. Mater. 21(18):3531-3539.

17. Gallone, G.; Carpi, F.; De Rossi, D.; Levita, G.; Marchetti, A. (2007) Dielectric constant enhancement in a silicone elastomer filled with lead magnesium niobate-lead titanate. Mater. Sci. Eng. C 27(1):110-116.

18. Seetapan, N.; Panyathammaporn, T. (2008) Ultraviolet Protection Characteristics of Silicone/Titanium Dioxide Composite Sheets. Macromol. Symp. 264, 50-53.

19. Nakade, M.; Ichihashi, K.; Ogawa, M. (2005) Preparation of Titania/PDMS Hybrid Films and the Conversion to Porous Materials. J. Sol-Gel Sci. Technol. 36:257-264.

20. Cazacu, M.; Antohi, M.; Racles, C.; Vlad, A.; Forna, N. (2009) Silicone-based composite for lining of removable dental prosthesis, J. Compos. Mater. 43(19), 2045-2055.

21. Warrik, E.L.; Pierce, O.R.; Polmanteer, K.E.; Saam, J.C. (1979) Silicone elastomer. Developments. Rubb. Chem. Technol. 52:437-525.

22. Freeman, G.G. (1962). In: Ritchie, P.D.; Barker, H. (eds) Silicones - An Introduction to their Chemistry and Applications. London-Ilife: Books LTD.

23. Gubbels, F. (2007) Silicones in Industrial Applications. In: De Jaeger, R.; Gleria, M. (eds) Inorganic Polymers, Nova Science Publishers, 2007. pp. 61-162 (chapter 2).

24. Kremer, F.; Schönhals, A.; Luck, W. (2002) Broadband Dielectric Spectroscopy. - SpringerVerlag, 2002.

25. Gallone, G.; Galantini, F.; Carpi, F. (2010) Perspectives for new dielectric elastomers with improved electromechanical actuation performance: composites versus blends. Polym. Int. 59: 400-406.

26. Moulson, A.J.; Herbert, J.M. (1990) Electroceramics: materials, properties and applications. London: Chapman \& Hall.

27. Hamciuc, C.; Hamciuc, E.; Cazacu, M.; Okrasa, L. (2008) Poly(ether-imide) and poly(etherimide)-polydimethyl-siloxane containing isopropylidene groups. Polym. Bull. 59:825-832.

28. Alexandru, M.; Cazacu, M.; Nistor, A.; Musteata, V.E.; Stoica, I.; Grigoras, C.; Simionescu, B.C. (2010) Polydimethylsiloxane/silica/titania composites prepared by solvent-free sol-gel 
technique. J. Sol-Gel Sci. Technol. 56:310-319.

29. Chen, K.; Yang, S. (2002) Synthesis of epoxy-montmorillonite nanocomposite. J. Appl. Polym. Sci. 86:414-21.

30. Liu, X.; Wu, Q. (2001) Pp/clay nanocomposites prepared by grafting-melt intercalation. Polymer 42:10013-10022.

31. Ash, B.; Schadler, L.; Siegel, R. (2002) Glass transition behavior of lumina/polymethylmethacrylate nanocomposites. Mater. Lett. 55:83-7.

32. Bershtein, V.; Egorova, L.; Yakushev, P.; Pissis, P.; Sysel, P.; Brozova, L. (2002) Molecular dynamics in nanostructured polyimide-silica hybrid materials and their thermal stability. $J$. Polym. Sci. Part B: Polym. Phys. 40:1056-1069.

33. Fragiadakis, D.; Pissis, P.; Bokobza, L. (2005) Glass transition and molecular dynamics in poly(dimethylsiloxane)/silica nanocomposites. Polymer 46:6001-6008.

34. Vogel, H. (1921) Das Temperaturabhängigkeitsgesetz der Viskosität von Flüssigkeiten. Physik Z. 22:645-646.

35. Liedermann, K. (1996) A simple formula for the temperature dependence of the relaxation frequency in glassy systems. Colloid Polym. Sci. 274:20-26.

36. Yang, G.; Ren, W.; Akhras, G.; Mukherjee, B.K. (2005) Transverse strain of silicone dielectric elastomer actuators. J. Adv. Sci. 18(1/2):166-169.

37. Granstrom, J.; Feenstra, J.; Sodano, H.A.; Farinholt, K. (2007) Energy harvesting from a backpack instrumented with piezoelectric shoulder straps. Smart Mater. Struct. 16:1810-1820.

38. Kwon, D.; Rincon-Mora, G.A. (2009) A rectifier-free piezoelectric energy harvester circuit. Proceedings of ISCAS 1085-1088.

39. Liu, Y.; Liu, L.; Zhang, Z.; Jiao, Y.; Sun, S.; Leng, J. (2010) Analysis and manufacture of an energy harvester based on a Mooney-Rivlin-type dielectric elastomer. Europhys. Lett. 90:36004. 


\section{Figure captions}

Figure 1. Stress-strain curves for the prepared samples: a-M1; b-M2; c-T3; d-1; e-2; f-3; g-4; h-5; i-6.

Figure 2. The dependence of storage modulus ( $\left.E^{\prime}\right)$, loss modulus ( $\left.E^{\prime \prime}\right)$ and tan $\delta$ on temperature for samples: a-M1; b-M2; c-T3; d-3.

Figure 3. Dielectric permittivity $\varepsilon$ ' as a function of frequency at room temperature for the samples: aM1; b-M2; c-T3; d-1; e-2; f-3; g-4; h-5; i-6.

Figure 4. Dielectric loss $\varepsilon "$ as a function of frequency at room temperature for the samples: a-M1; bM2; c-T3; d-1; e-2; f-3; g-4; h-5; i-6.

Figure 5. Dielectric constant (a) and dielectric loss (b) as a function of frequency and temperature for composite 4.

Figure 6. Temperature dependence of dielectric loss for the samples: a-M1; b-M2; c-T3; d-1; e-2; f-3; g-4; h-5; i-6.

Figure 7. Arrhenius plot representing $\ln f_{\max }$ vs. $1 / T$ for samples M1, M2 and $1-6$.

Figure 8. The illustrative shapes of the moisture sorption-desorption isotherms: a-T3; b-4.

Figure 9. The displacement versus applied voltage for the prepared samples: a-M1; b-M2; c-T3; d-1; e$2 ; \mathrm{f}-3 ; \mathrm{g}-4 ; \mathrm{h}-5 ; \mathrm{i}-6$.

Figure 10. Schematic energy harvester based on silicone elastomer film. 
Table 1. The prepared samples

\begin{tabular}{cccccccccc}
\hline Sample & $\mathbf{M 1}$ & $\mathbf{M 2}$ & $\mathbf{T 3}$ & $\mathbf{1}$ & $\mathbf{2}$ & $\mathbf{3}$ & $\mathbf{4}$ & $\mathbf{5}$ & $\mathbf{6}$ \\
\hline $\mathrm{PDMS}, \mathrm{pph}$ & 100 & 100 & 100 & 100 & 100 & 100 & 100 & 100 & 100 \\
\hline $\mathrm{SiO}_{2}, \mathrm{pph}$ & 0 & 28 & - & 28 & 28 & 28 & 28 & 28 & 28 \\
\hline $\mathrm{TiO}_{2}, \mathrm{pph}$ & 0 & 0 & 10 & 2 & 6 & 10 & 20 & 30 & 50 \\
\hline
\end{tabular}


Table 2. The main parameters of the mechanical tests

\begin{tabular}{|c|c|c|c|c|}
\hline Sample & $\begin{array}{c}\text { Young's modulus, }^{\text {a }} \\
\text { MPa }\end{array}$ & $\begin{array}{c}\text { Tensile strength, } \\
\text { MPa }\end{array}$ & $\begin{array}{c}\text { Elongation at } \\
\text { break, } \\
\%\end{array}$ & $\begin{array}{l}\text { Hardness, } \\
{ }^{\circ} \mathrm{Sh} A\end{array}$ \\
\hline M1 & 0.63 & 0.31 & 90 & 62.0 \\
\hline M2 & 1.97 & 1.24 & 128 & 83.0 \\
\hline T3 & 0.23 & 0.32 & 160 & 46.5 \\
\hline 1 & 1.42 & 3.22 & 312 & 72.6 \\
\hline 2 & 1.13 & 2.79 & 313 & 74.4 \\
\hline 3 & 1.37 & 3.91 & 406 & 77.7 \\
\hline 4 & 0.97 & 3.16 & 363 & 81.4 \\
\hline 5 & 1.32 & 4.89 & 589 & 84.0 \\
\hline 6 & 1.02 & 4.53 & 635 & 86.0 \\
\hline
\end{tabular}


Table 3. The main parameters of DMA curves

\begin{tabular}{ccccc}
\hline Sample & $\mathbf{T}_{\mathbf{g}}$ & $\mathbf{T}_{\mathbf{m}}\left({ }^{\mathbf{0}} \mathbf{C}\right)$ & $\mathbf{E}^{\prime}(\mathbf{P a}) \mathbf{a t} \mathbf{- 1 4 0}{ }^{\mathbf{0}} \mathbf{C}$ & $\mathbf{E}^{\prime}(\mathbf{P a}) \mathbf{a t} \mathbf{2 5}{ }^{\mathbf{0}} \mathbf{C}$ \\
\hline $\mathbf{M 1}$ & -125 & -43 & $9.60 \mathrm{E}+08$ & $2.53 \mathrm{E}+06$ \\
\hline $\mathbf{M} 2$ & -125 & -41 & $1.36 \mathrm{E}+09$ & $5.11 \mathrm{E}+06$ \\
\hline $\mathbf{T 3}$ & -122 & -42 & $2.88 \mathrm{E}+09$ & $4.65 \mathrm{E}+05$ \\
\hline $\mathbf{1}$ & -126 & -40 & $2.17 \mathrm{E}+09$ & $1.63 \mathrm{E}+06$ \\
\hline $\mathbf{2}$ & -123 & -40 & $4.15 \mathrm{E}+09$ & $1.73 \mathrm{E}+06$ \\
\hline $\mathbf{3}$ & -124 & -40 & $3.96 \mathrm{E}+09$ & $1.20 \mathrm{E}+06$ \\
\hline $\mathbf{4}$ & -124 & -38 & $4.99 \mathrm{E}+09$ & $1.61 \mathrm{E}+06$ \\
\hline $\mathbf{5}$ & -125 & -38 & $6.47 \mathrm{E}+09$ & $2.05 \mathrm{E}+06$ \\
\hline $\mathbf{6}$ & -125 & -37 & $5.33 \mathrm{E}+09$ & $2.58 \mathrm{E}+06$ \\
\hline
\end{tabular}


Table 4. Maximum water vapor sorption capacity estimated on the basis of isotherms.

\begin{tabular}{cc}
\hline Sample & Weight $\left(\% \mathbf{d . b .}{ }^{\mathbf{a}}\right)$ \\
\hline M1 & 0.10 \\
\hline M2 & 0.47 \\
\hline T3 & 0.34 \\
\hline 1 & 0.35 \\
\hline 2 & 0.68 \\
\hline 3 & 0.40 \\
\hline 4 & 0.51 \\
\hline 5 & 0.38 \\
\hline 6 & 0.43 \\
\hline
\end{tabular}

${ }^{\mathrm{a}}$ dry basis 
Table 5. The main actuation and energy harvesting parameters.

\begin{tabular}{|c|c|c|c|c|}
\hline \multirow[t]{3}{*}{ Sample } & \multicolumn{3}{|c|}{ Actuation (at applied voltage $\mathrm{U}=500 \mathrm{~V}$ ) } & \multirow{3}{*}{$\begin{array}{c}\text { Harvesting } \\
\text { Voltage peak to peak, } \\
U_{p p}[V]\end{array}$} \\
\hline & & $\mathbf{E}$ & $R_{a}\left(a_{\max }\right)$ & \\
\hline & $\begin{array}{c}\text { Thickness } \\
\text { [mm] }\end{array}$ & $\begin{array}{c}\text { Electric field } \\
\text { [V/mm] }\end{array}$ & $\begin{array}{c}\text { Resolution }[\mathrm{nm} / \mathrm{V} / \mathrm{mm}] \\
\text { (maximum actuation, } \mathrm{nm} \text { ) }\end{array}$ & \\
\hline M1 & 1.60 & 313 & $0.10(30)$ & 8 \\
\hline M2 & 2.22 & 226 & $0.04(10)$ & 6 \\
\hline T3 & 1.43 & 350 & $1.06(370)$ & 10 \\
\hline 1 & 1.03 & 485 & $1.24(640)$ & 20 \\
\hline 2 & 0.78 & 641 & $2.31(900)$ & 16 \\
\hline 3 & 0.98 & 510 & $1.84(900)$ & 15 \\
\hline 4 & 1.08 & 463 & $3.33(1800)$ & 14 \\
\hline 5 & 1.01 & 495 & $2.57(1300)$ & 12 \\
\hline 6 & 0.98 & 510 & $5.09(2496)$ & 14 \\
\hline
\end{tabular}




1
2
3
4
5
6
7
8
9
10
11
12
13
14
15
16
17
18
19
20
21
22
23
24
25
26
27
28
29
30
31
32
33
34
35
36
37
38
39
40
41
42
43
44
45
46
47
48
49
50
51
52
53
54
55
56
57
59
60

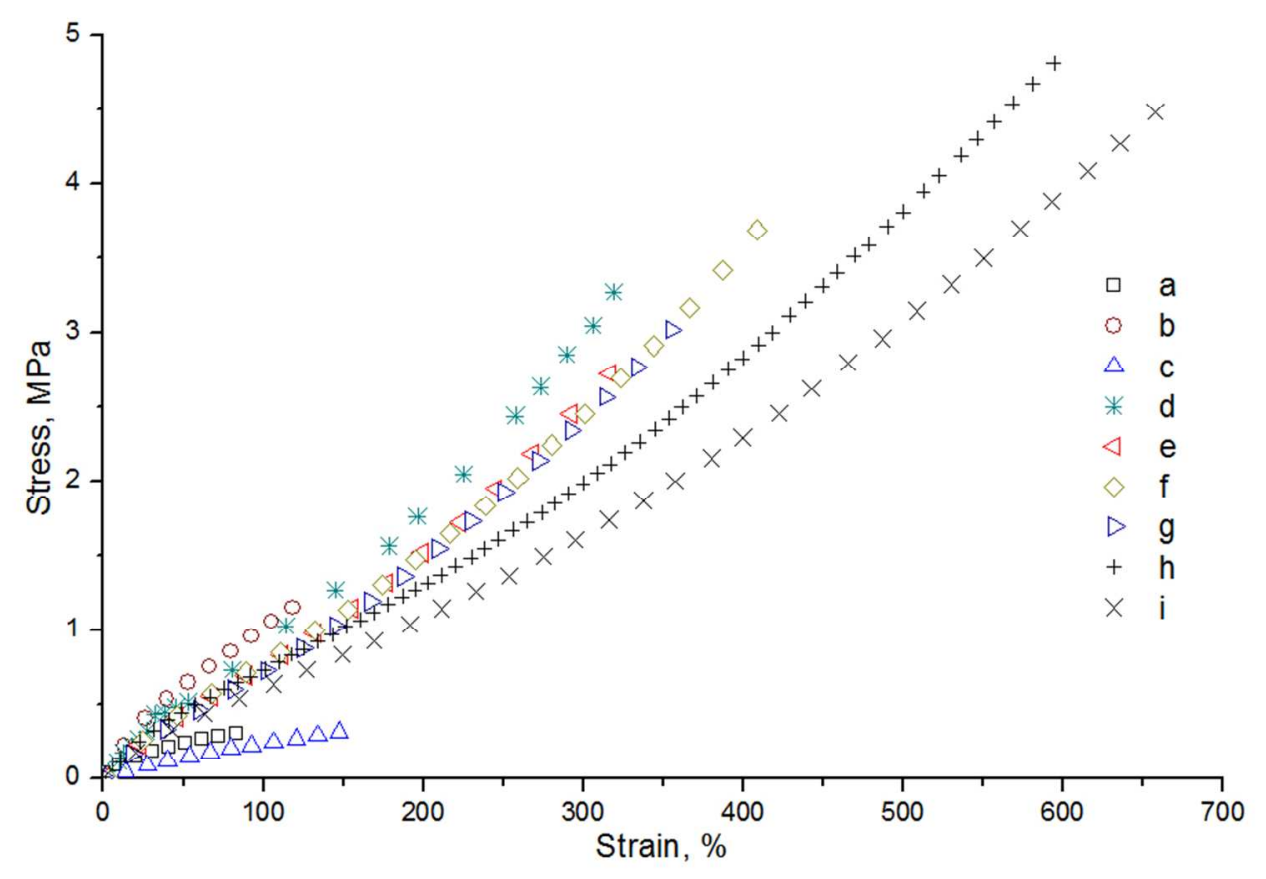

Figure 1. Stress-strain curves for the prepared samples: a-M1; b-M2; c-T3; d-1; e-2; f-3; g-4; h-5; i-6 $79 \times 56 \mathrm{~mm}(300 \times 300 \mathrm{DPI})$ 
Figure 2. The dependence of storage modulus $\left(E^{\prime}\right)$, loss modulus ( $\left.E^{\prime \prime}\right)$ and tan $\delta$ on temperature for samples: a-M1; b-M2; C-T3; d-3 $152 \times 152 \mathrm{~mm}(300 \times 300 \mathrm{DPI})$ 


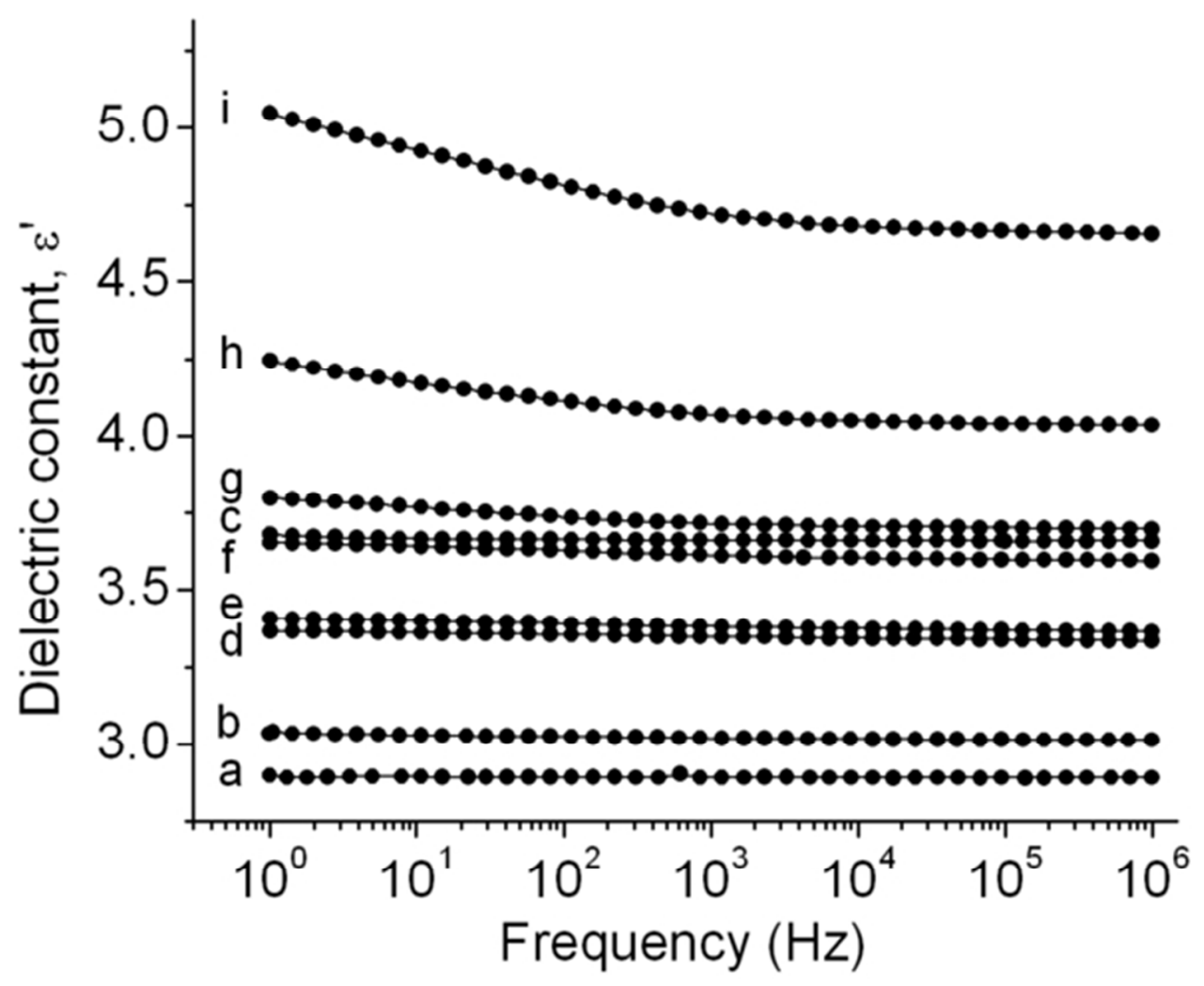

Figure 3. Dielectric permittivity $\varepsilon^{\prime}$ as a function of frequency at room temperature for the samples: a-M1; bM2; c-T3; d-1; e-2; f-3; g-4; h-5; i-6 $26 \times 21 \mathrm{~mm}(600 \times 600 \mathrm{DPI})$ 


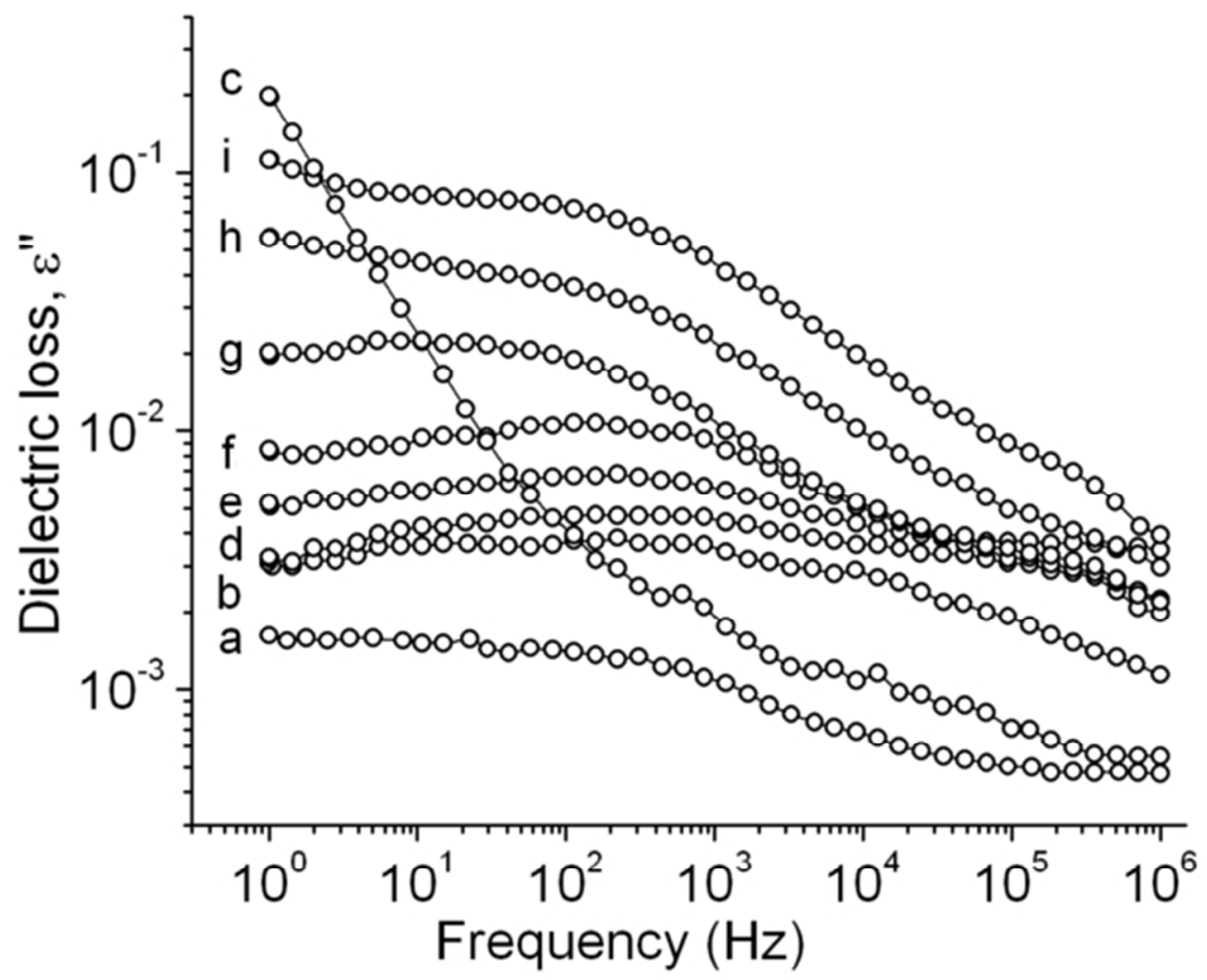

Figure 4. Dielectric loss $\varepsilon^{\prime \prime}$ as a function of frequency at room temperature for the samples: a-M1; b-M2; c-

T3; d-1; e-2; f-3; g-4; h-5; i-6 $26 \times 21 \mathrm{~mm}(600 \times 600$ DPI $)$ 

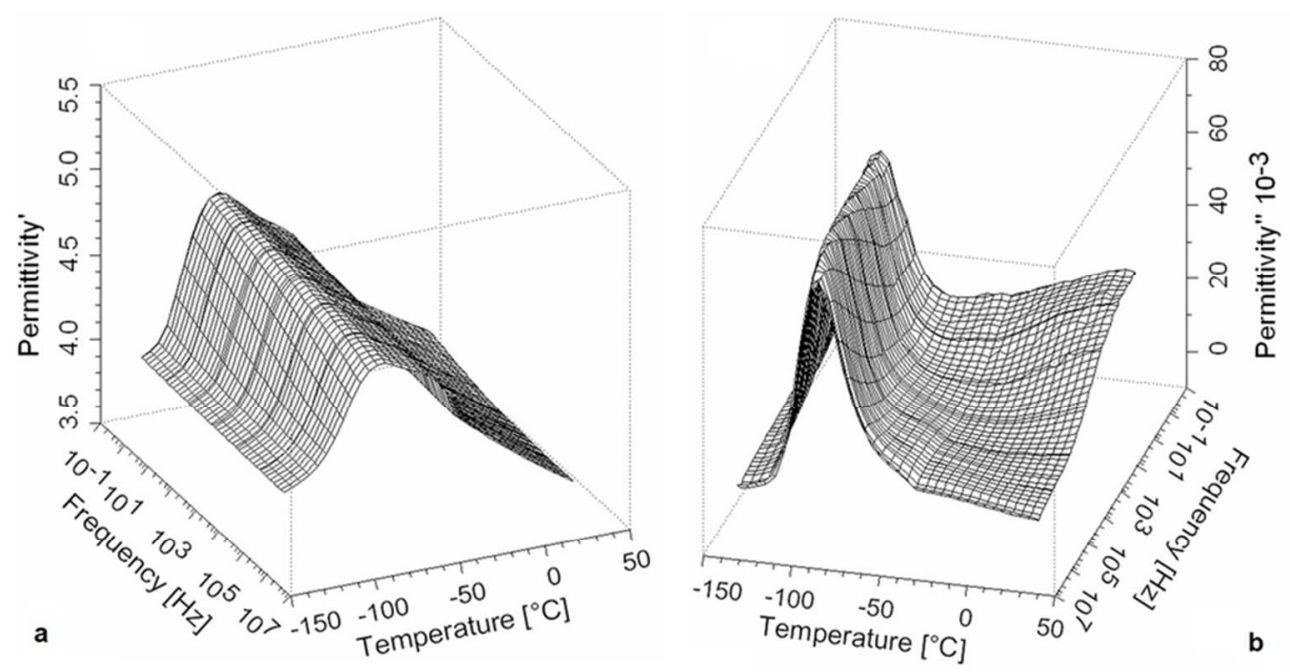

Figure 5. Dielectric constant (a) and dielectric loss (b) as a function of frequency and temperature for composite 4 $77 \times 39 \mathrm{~mm}(300 \times 300 \mathrm{DPI})$ 


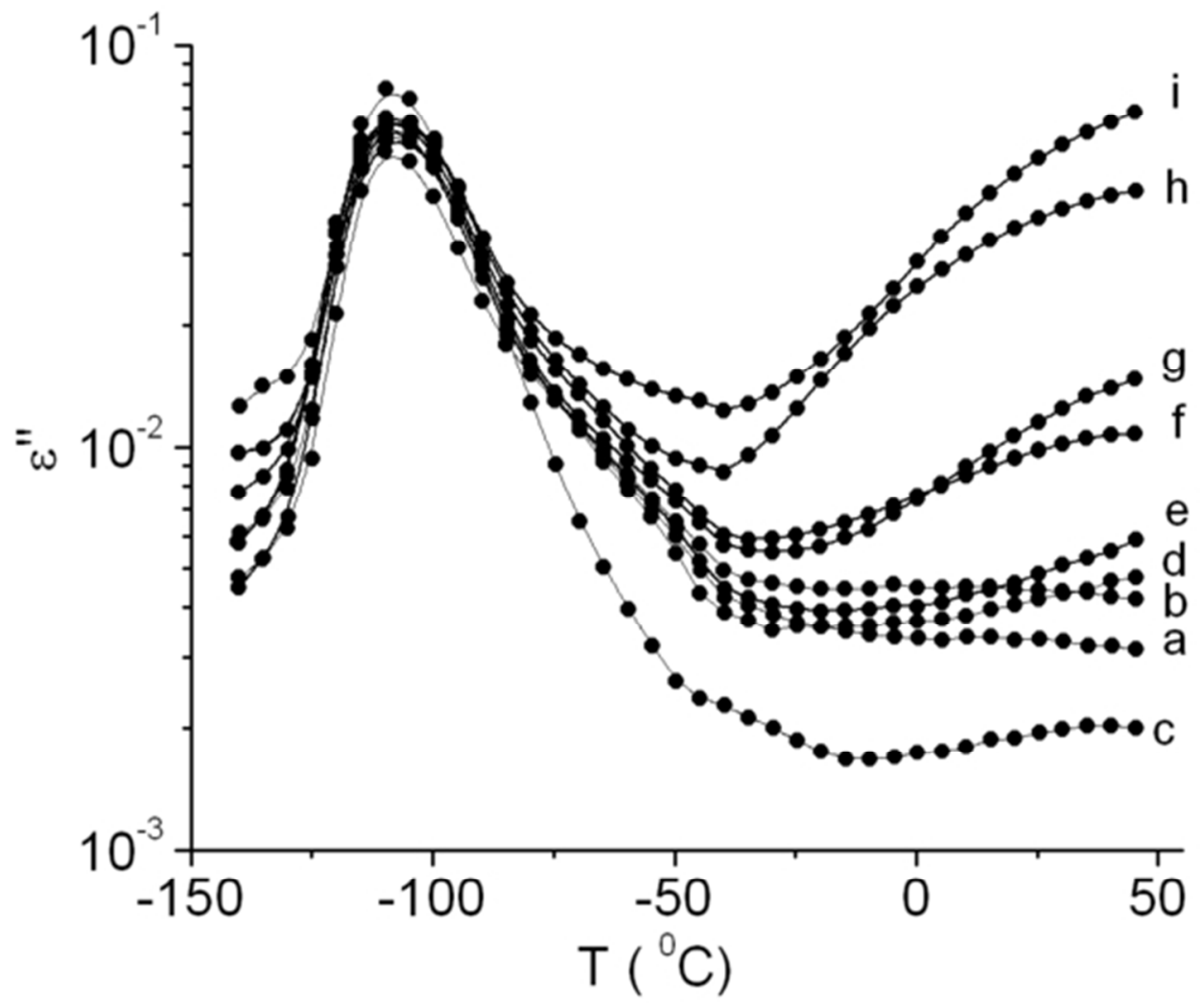

Figure 6. Temperature dependence of dielectric loss for the samples: a-M1; b-M2;c-T3; d-1; e-2; f-3; g-4; h-5; i-6

$25 \times 20 \mathrm{~mm}(600 \times 600 \mathrm{DPI})$ 


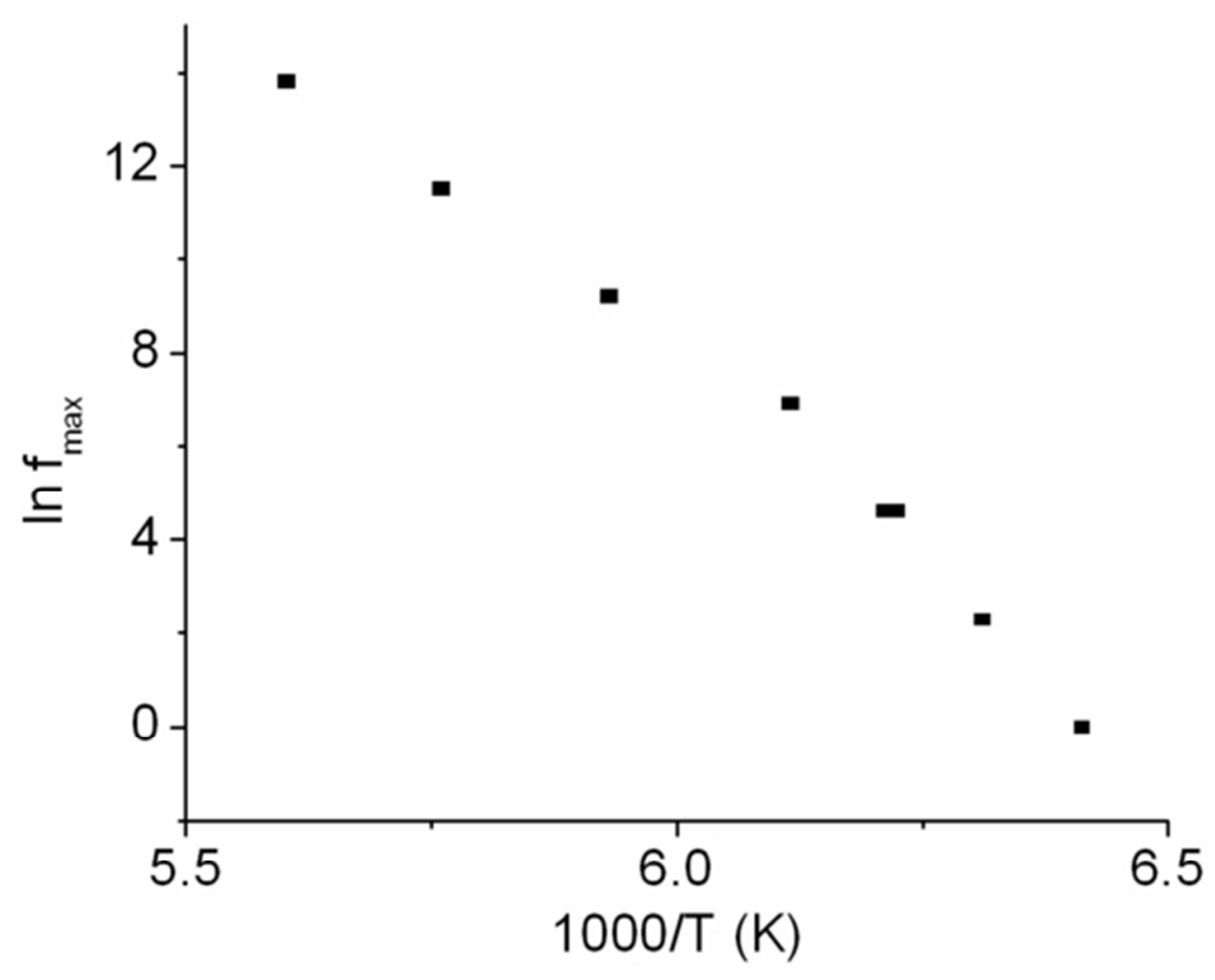

Figure 7. Arrhenius plot representing In fmax vs. $1 /$ T for samples M1, M2 and $1-6$ $24 \times 19 \mathrm{~mm}(600 \times 600 \mathrm{DPI})$ 
1

2

3

4

5

6

7

8

9

10

11

12

13

14

15

16

17

18

19

20

21

22

23

24

25

26

27

28

29

30

31

32

33

34

35

36

37

38

39

40

41

42

43

44

45

46

47

48

49

50

51

52

53

54

55

56

57

58

59

60

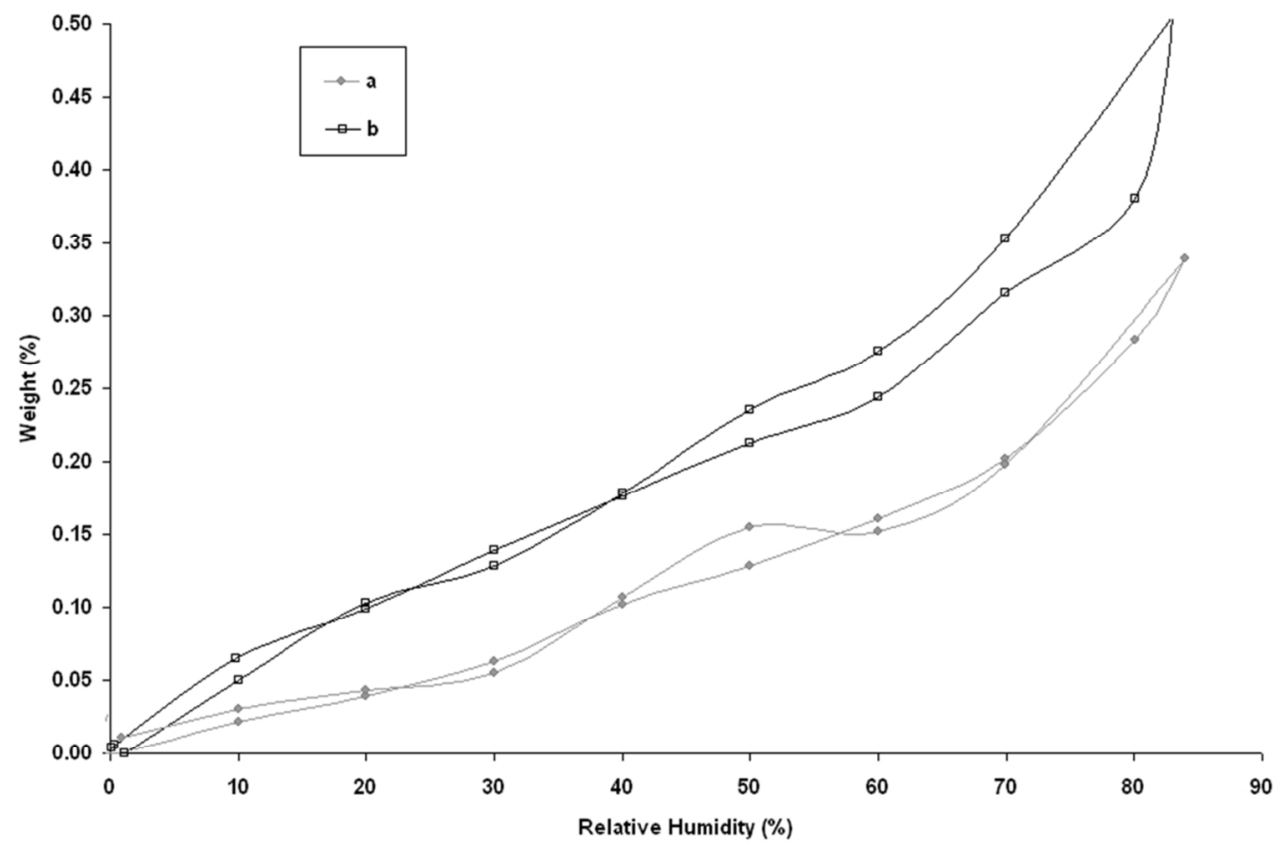

Figure 8 . The illustrative shapes of the moisture sorption-desorption isotherms: a-T3; b-4 $104 \times 71 \mathrm{~mm}(300 \times 300 \mathrm{DPI})$ 


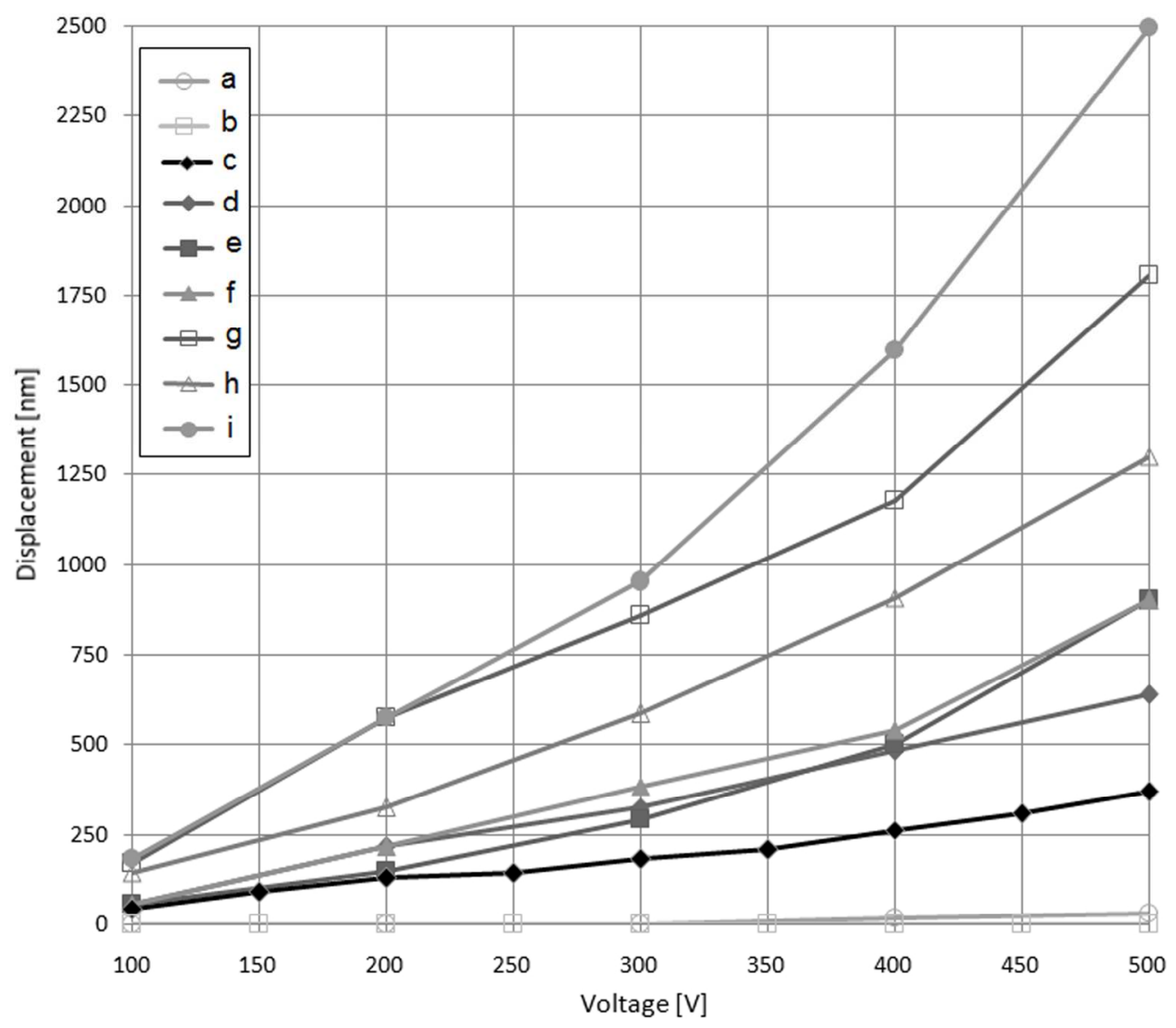

Figure 9. The displacement versus applied voltage for the prepared samples: a-M1; b-M2; c-T3; d-1; e-2; f$3 ; \mathrm{g}-4 ; \mathrm{h}-5 ; \mathrm{i}-6$ $135 \times 121 \mathrm{~mm}(300 \times 300$ DPI $)$ 


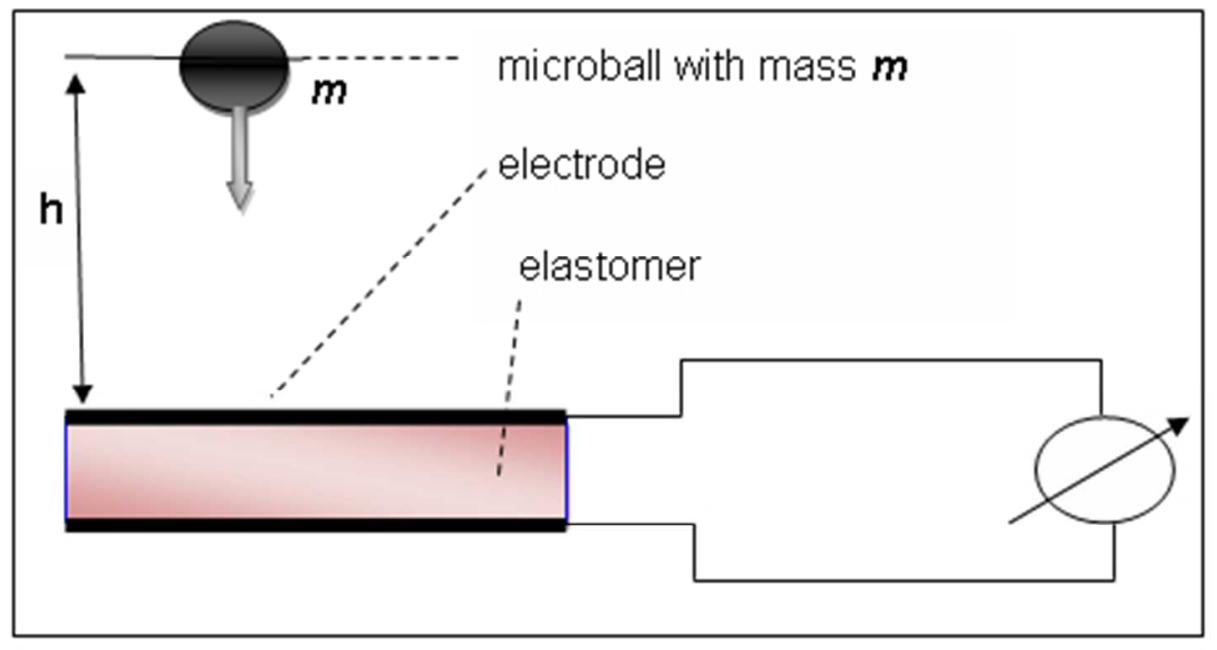

Figure 10. Schematic energy harvester based on silicone elastomer film 